Tạp chí Khoa học và Công nghệ biển T10 (2010). Số 4. Tr 01 - 13

\title{
CHẤT LƯợNG MÔI TRƯờnG TRÀ̀M TÍCH ĐẦM TH!̣ NẠI, TỈNH BÌNH ĐỊNH
}

\author{
LÊ TH!̣ VINH, NGUYẼ̃N TH!̣ THANH THỦY, TỐNG PHƯỚC HOÀNG SƠN \\ DƯƠNG TRỌNG KIỂM, NGUYẼ̃N HỒNG THU, PHẠM HŨU TÂM, PHẠM HỔNG NGỌC
}

Viện Hải dương học

\begin{abstract}
Tóm tắt: Nội dung bài báo trình bày một số kết quả nghiên cưu chất luợng môi truờng trầm tích đầm Thị Nại vào tháng 11/2008 (mùa mura) và tháng 4/2009 (mùa khô). Tù kết quả phân tích cho thấy hàm lương các chất hũu co và kim loại nặng trong trầm tích đầm Thị Nại biến đổi trong phạm vi rộng (C hũu co tù 0,09 - 1,16\%, $N$ hũu co tù 88,7 - 1826,0 $\mu \mathrm{g} / \mathrm{g}, P$ tổng số tù̀ 44,2 - 938,2 $\mu \mathrm{g} / \mathrm{g}$, Zn tù 3,4 - 75,6 $\mu \mathrm{g} / \mathrm{g}$, hydrocarbon tù 108 - $423 \mu \mathrm{g} / \mathrm{g}$, Cu tù 0,1 $15,3 \mu \mathrm{g} / \mathrm{g}, \mathrm{Pb}$ tù̀ 2,3 - 35,2 $\mu \mathrm{g} / \mathrm{g}$, Fe tù̀ 1379 - $14981 \mu \mathrm{g} / \mathrm{g}$ ), có xu huóng tăng dần tù đỉnh đầm về phía cửa đầm và có mối quan hệ mật thiết với độ hạt của trầm tích. Hàm luợng của chúng cao trong trầm tích bùn sét và thấp hơn trong trầm tích hạt thô. Vật chất hũu co trong trầm tích chủ yếu có nguồn gốc lục nguyên (terrigeneous organic matter).

Chất luợng môi truờng trầm tích đầm Thị Nại còn khá tốt, hàm luợng các chất hữu co và kim loại nặng trong trầm tích đầm Thị Nại đều phù hợp cho đời sống thủy sinh.

Các yếu tố ảnh huơơng đến chất luợng môi truờng trầm tích gồm vật chất tù̀ tư nhiên (chủ yếu là vật chất tù sông Côn và sông Hà Thanh) và tù các hoạt động kinh tế - xã hội trong khu vục liền kề.Vào thờ kỳ mua lũ, sụ lắng đọng vật chất xảy ra trong toàn đầm, nhung vào mùa khô hiện tuợng này chủ yếu diễn ra trong khu vưc đỉnh đầm. Tốc độ lắng đọng trầm tích (TĐLĐTT) vào mùa mura cao hơn so với mùa khô nhung hàm luợng các chất hũu co và kim loại nặng trong vật liệu trầm tích mói lắng đọng vào mùa mua lại thấp hơn.
\end{abstract}

\section{MỞ ĐÀ̀U}

Đầm Thị Nại, diện tích trên 5.060 ha, là đầm lớn thứ 2 trong số các đầm phá ở Việt Nam. Đây là một đầm khá kín, chịu ảnh hưởng của chế độ bán nhật triều, có chiều dài khoảng $15,5 \mathrm{~km}$, chiều rộng lớn nhất khoảng $6 \mathrm{~km}$. Mạng lưới sông suối đổ vào đầm khá dày đặc và tập trung chủ yếu ở phía Tây, trong đó có 2 con sông chính là sông Côn và Hà Thanh. Nuôi trồng và khai thác thủy sản trong đầm đã góp phần đáng kể vào tăng trưởng kinh tế chung của tỉnh Bình Định. Tuy nhiên, cùng với sự phát triển kinh tế-xã hội của tỉnh, quá trình đô thị hóa khu vực quanh đầm, kéo theo các hoạt động du lịch dịch vụ, giao thông vận tải, sản xuất nông nghiệp, sinh hoạt dân cư..., đã làm phát sinh những vấn đề về môi trường. 
Một số nghiên cứu về chất lượng nước đầm Thị Nại đã được công bố trong thời gian trước đây (Nguyễn Hữu Huân, 2007; Lê Thị Vinh và Nguyễn Thị Thanh Thủy, 2009) trong lúc chất lượng môi trường trầm tích của đầm hầu như chưa được đề cập. Nhằm cung cấp đầy đủ thông tin về chất lượng môi trường đầm Thị Nại, nội dung bài báo này sẽ đề cập đến một số vấn đề liên quan đến chất lượng trầm tích đầm này. Các dẫn liệu trong nội dung bài báo là một phần các kết quả nghiên cứu của nhiệm vụ "Nghiên cúu cơ sở khoa học nhằm xây dựng các giải pháp phát triển nuôi trồng thủy sản bền vũng tại đầm Thị Nại, tỉnh Bình Định" đã được Viện Hải dương học thực hiện trong hai năm 2008 - 2009.

\section{PHƯONG PHÁP NGHIÊN CÚU}

\section{Thu mẫu}

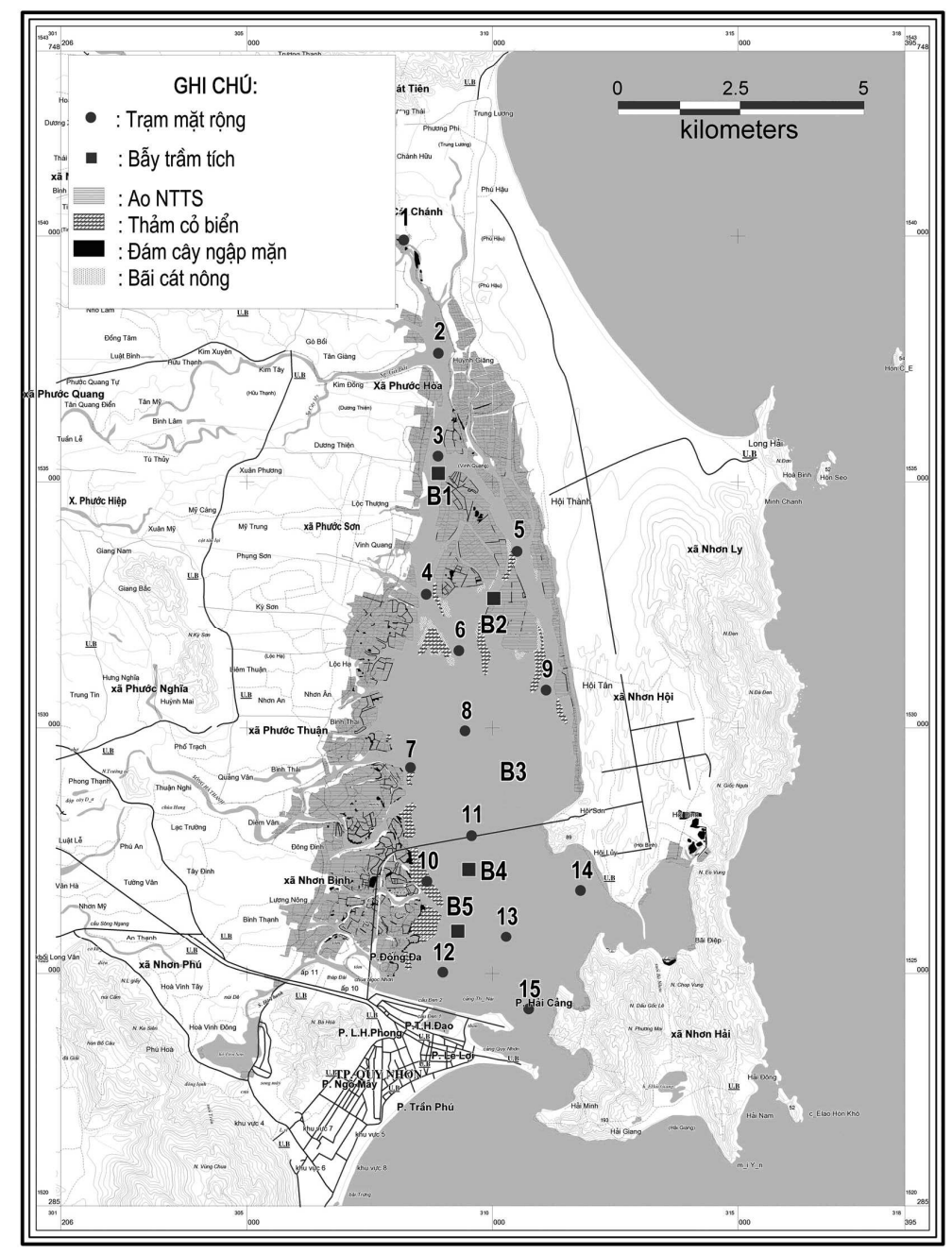

Hình 1: Vị trí các trạm thu mẫu 
Mẫu trầm tích được thu trong hai đợt khảo sát chính (mỗi đợt 15 mẫu) được tiến hành vào mùa mưa (tháng 11/2008) và mùa khô (tháng 4/2009). Hai đợt khảo sát bổ sung vào $11 / 2008$ và $5 / 2009$ cũng được tiến hành để thu mẫu vật lơ lửng (các trạm $2,5,8,11$ và 15) và vật liệu mới lắng đọng dọc theo trục đầm.

Các mẫu trầm tích được thu bằng cuốc thu mẫu. Mẫu vật liệu mới lắng đọng được thu bằng bẫy trầm tích có đường kính $8,5 \mathrm{~cm}$, cao $40 \mathrm{~cm}$ (diện tích $56,745 \mathrm{~cm}^{2}$ ) được làm bằng plastic, mỗi bẫy gồm có 3 ống, thời gian đặt bẫy liên tục 5 ngày đêm. Mẫu vật lơ lửng được thu bằng bathomet và lọc qua màng lọc $0,45 \mathrm{~mm}$. Vị trí các trạm thu mẫu được trình bày trong hình 1 .

\section{Bảo quản, phân tích mẫu và tính tốc độ lắng đọng trầm tích (TĐLĐTT)}

Các mẫu được xử lý, bảo quản và phân tích theo các phương pháp tiêu chuẩn hiện hành (FAO, 1975). Các chỉ tiêu phân tích gồm thành phần độ hạt trầm tích. Hàm lượng $\mathrm{C}$ hữu cơ, $\mathrm{N}$ hữu cơ, $\mathrm{P}$ tổng số, một số kim loại nặng $(\mathrm{Zn}, \mathrm{Cu}, \mathrm{Pb}$ và $\mathrm{Fe})$ và hydrocarbon (HC) trong trầm tích. TĐLĐTT) được tính bằng công thức sau:

$$
\text { Khối lượng (g khô) trong bẫy }
$$

$$
\text { TĐLĐTT }\left(\mathrm{g} / \mathrm{cm}^{2} / \text { ngày }\right)=\frac{\text { Diện tích bẫy }\left(\mathrm{cm}^{2}\right) \text { x thời gian đặt bẫy (ngày) }}{\text { Tàn }}
$$

\section{KẾT QUẢ NGHIÊN CÚU}

\section{Thành phần cơ học của trầm tích}

Dựa trên sự khác biệt về địa hình và một số yếu tố ảnh hưởng trực tiếp đến chất lượng môi trường trầm tích, đầm Thị Nại được phân biệt thành 3 khu vực :

- Khu vực đỉnh đầm bao gồm các trạm 1 đến trạm 5 , khu vực này rất hẹp, có sông Côn đổ vào và chịu nhiều ảnh hưởng của đất liền;

- Khu vực giữa đầm bao gồm các trạm trạm 6 đến trạm 10 có diện tích rộng hơn và chịu ảnh hưởng trực tiếp của nước sông Hà Thanh;

- Khu vực cửa đầm gồm các trạm 11 đến trạm 15 , có sự trao đổi với biển khơi.

Kết quả phân tích thành phần cơ học của trầm tích được trình bày trong bảng 1 . Từ các kết quả trong bảng này có thể thấy là trầm tích tại khu vực đỉnh đầm được cấu tạo chủ yếu bởi vật liệu cát. Trầm tích trong khu vực giữa đầm được cấu tạo chủ yếu bởi cát chứa bùn sét và trầm tích cửa đầm được cấu tạo bởi trầm tích bùn sét chứa cát. 
Bảng 1: Giá trị trung bình của thành phần cơ học trầm tích đầm Thị Nại (đợt khảo sát tháng 11/2008 và 4/2009)

\begin{tabular}{|c|c|c|c|c|c|}
\hline Khu vực & & $\mathbf{> 0 , 2 5} \mathbf{~ m m}$ & $\mathbf{0 , 2 5} \mathbf{- 0 , 0 6 3} \mathbf{~ m m}$ & $<\mathbf{0 , 0 6 3} \mathbf{~ m m}$ & Trầm tích chủ yếu \\
\hline Đỉnh & $\mathrm{TB}$ & 76,38 & 17,48 & 6,13 & Cát \\
đầm & $\mathrm{CT}$ & 52,95 & 3,67 & 0 & \\
& $\mathrm{C}$ & 96,33 & 36,96 & 35,23 & \\
& $\mathrm{n}$ & 5 & 5 & 5 & \\
\hline Giữa & $\mathrm{TB}$ & 20,88 & 50,79 & 28,33 & Cát chứa bùn sét \\
đầm & $\mathrm{CT}$ & 4,18 & 24,97 & 1,63 & \\
& $\mathrm{C}$ & 52,74 & 77,39 & 70,25 & \\
& $\mathrm{n}$ & 5 & 5 & 5 & \\
\hline Cửa & $\mathrm{TB}$ & 11,66 & 13,84 & 74,50 & Bùn sét chứa cát \\
đầm & $\mathrm{CT}$ & 1,39 & 5,09 & 43,09 & \\
& $\mathrm{C}$ & 24,28 & 32,63 & 93,52 & \\
& $\mathrm{n}$ & 5 & 5 & 5 & \\
& & \multicolumn{3}{|r}{} \\
\hline
\end{tabular}

\section{Thành phần hóa học trong trầm tích}

Bảng 2: Thành phần của trầm tích (mùa mưa, tháng 11/2008)

\begin{tabular}{|c|c|c|c|c|c|c|c|c|c|c|}
\hline & $\begin{array}{l}\text { Giá } \\
\text { Trị }\end{array}$ & $\begin{array}{l}\text { C.hc } \\
(\%)\end{array}$ & $\begin{array}{c}\text { N hữu } \\
\text { co } \\
\mu \mathrm{g} / \mathrm{g}\end{array}$ & $\begin{array}{c}\text { P tổng } \\
\mu \mathrm{g} / \mathrm{g}\end{array}$ & $\begin{array}{c}\mathrm{Zn} \\
\mu \mathrm{g} / \mathrm{g}\end{array}$ & $\begin{array}{c}\mathrm{Cu} \\
\mu \mathrm{g} / \mathrm{g}\end{array}$ & $\begin{array}{c}P b \\
\mu g / g\end{array}$ & $\begin{array}{c}\mathrm{Fe} \\
\mu \mathrm{g} / \mathrm{g}\end{array}$ & $\begin{array}{r}\mathrm{HC} \\
\mu \mathrm{g} / \mathrm{g}\end{array}$ & $\begin{array}{c}\text { Tỷ lệ } \\
\text { bùn- } \\
\text { sét (\%) }\end{array}$ \\
\hline \multirow{4}{*}{$\begin{array}{l}\text { Đỉnh } \\
\text { đầm }\end{array}$} & TB & 0,17 & 140,3 & 72,0 & 7,9 & 1,3 & 3,4 & 3109 & 229 & 1,3 \\
\hline & $\mathrm{CT}$ & 0,09 & 95,6 & 44,2 & 3,4 & 0,1 & 2,3 & 1379 & 108 & 0,0 \\
\hline & $\mathrm{CĐ}$ & 0,26 & 201,3 & 100,5 & 20,0 & 4,1 & 7,2 & 7395 & 379 & 4,13 \\
\hline & $\mathrm{n}$ & 5 & 5 & 5 & 5 & 5 & 5 & 5 & 5 & 5 \\
\hline \multirow{4}{*}{$\begin{array}{l}\text { Giữa } \\
\text { đầm }\end{array}$} & TB & 0,45 & 494,7 & 274,0 & 46,9 & 4,9 & 13,4 & 7543 & 265 & 21,4 \\
\hline & $\mathrm{CT}$ & 0,18 & 205,5 & 84,3 & 15,7 & 0,6 & 3,1 & 2479 & 169 & 3,0 \\
\hline & $\mathrm{CĐ}$ & 0,88 & 1219,5 & 689,7 & 83,0 & 10,7 & 26,0 & 11633 & 338 & 69,6 \\
\hline & $\mathrm{n}$ & 5 & 5 & 5 & 5 & 5 & 5 & 5 & 5 & 5 \\
\hline \multirow{4}{*}{$\begin{array}{l}\text { Cửa } \\
\text { đầm }\end{array}$} & TB & 0,98 & 1186,1 & 681,4 & 54,1 & 10,8 & 27,3 & 11959 & 376 & 74,3 \\
\hline & CT & 0,73 & 560,00 & 371,0 & 40,1 & 7,0 & 17,4 & 9270 & 310 & 43,1 \\
\hline & $\mathrm{CĐ}$ & 1,16 & 1675,0 & 886,1 & 66,7 & 15,3 & 35,2 & 14981 & 423 & 93,5 \\
\hline & $\mathrm{n}$ & 5 & 5 & 5 & 5 & 5 & 5 & 5 & 5 & 5 \\
\hline
\end{tabular}


Mùa mua: Kết quả phân tích các mẫu trầm tích thu vào mùa mưa (bảng 2) cho thấy hàm lượng các chất hữu cơ, kim loại nặng và hydrocarbon trong trầm tích có xu thế tăng dần từ đỉnh đầm về phía cửa đầm.

Mùa khô: Tương tự như mùa mưa, xu thế phân bố các chất hữu cơ, kim loại nặng và HC cũng có xu thế tương tự và cao nhất tại khu vực cửa đầm (bảng 3 ). So sánh kết quả giữa 2 đợt khảo sát cho thấy hàm lượng của tất cả các thông số khảo sát đều cao vào tháng $5 / 2009$ (trừ $\mathrm{HC}$ ), tỷ lệ bùn sét cũng cao hơn. Trong cả 2 đợt khảo sát đều có sự gia tăng rất rõ ràng của hàm lượng các chất hữu cơ, kim loại nặng trong trầm tích theo dọc theo trục đầm, từ đỉnh đầm về phía cửa đầm.

Bảng 3: Thành phần trầm tích của đầm Thị Nại vào mùa khô (tháng 4/2009)

\begin{tabular}{|c|c|c|c|c|c|c|c|c|c|c|}
\hline $\begin{array}{l}\text { Khu } \\
\text { vục }\end{array}$ & $\begin{array}{l}\text { Giá } \\
\text { Trị }\end{array}$ & $\begin{array}{l}\text { C.hc } \\
(\%)\end{array}$ & $\begin{array}{l}\text { Nhc } \\
\mu \mathrm{g} / \mathrm{g}\end{array}$ & $\begin{array}{c}\text { Pts } \\
\mu \mathrm{g} / \mathrm{g}\end{array}$ & $\begin{array}{c}\mathrm{Zn} \\
\mu \mathrm{g} / \mathrm{g}\end{array}$ & $\begin{array}{c}\mathrm{Cu} \\
\mu \mathrm{g} / \mathrm{g}\end{array}$ & $\begin{array}{c}\mathrm{Pb} \\
\mu \mathrm{g} / \mathrm{g}\end{array}$ & $\begin{array}{c}\mathrm{Fe} \\
\mu \mathrm{g} / \mathrm{g}\end{array}$ & $\begin{array}{c}\mathrm{HC} \\
\mu \mathrm{g} / \mathrm{g}\end{array}$ & $\begin{array}{c}\text { Tỷ lệ } \\
\text { bùn- } \\
\text { sét }(\%)\end{array}$ \\
\hline \multirow{4}{*}{$\begin{array}{l}\text { Đỉnh } \\
\text { dầm }\end{array}$} & TB & 0,39 & 236,5 & 123,9 & 18,4 & 2,8 & 6,3 & 5447 & 179 & 10,9 \\
\hline & CT & 0,14 & 88,7 & 52,5 & 7,9 & 1,1 & 2,8 & 3353 & 127 & 0,1 \\
\hline & $\mathrm{C} \bigoplus$ & 0,91 & 482,7 & 259,3 & 39,5 & 5,4 & 13,2 & 10140 & 289 & 35,2 \\
\hline & $\mathrm{n}$ & 5 & 5 & 5 & 5 & 5 & 5 & 5 & 5 & 5 \\
\hline \multirow{4}{*}{$\begin{array}{l}\text { Giữa } \\
\text { dầm }\end{array}$} & TB & 0,71 & 797,2 & 527,8 & 41,3 & 6,3 & 15,3 & 8608 & 230 & 35,3 \\
\hline & $\mathrm{CT}$ & 0,27 & 190,0 & 59,6 & 9,6 & 0,9 & 3,4 & 3057 & 151 & 1,63 \\
\hline & $\mathrm{C} Ð$ & 1,12 & 1400,0 & 937,5 & 65,2 & 11,6 & 26,9 & 12723 & 335 & 70,2 \\
\hline & $\mathrm{n}$ & 5 & 5.0 & 5.0 & 5 & 5 & 5 & 5 & 5 & 5 \\
\hline \multirow{4}{*}{$\begin{array}{l}\text { Cửa } \\
\text { đầm }\end{array}$} & TB & 0,97 & 1664,6 & 845,1 & 56,9 & 10,9 & 29,7 & 12183 & 289 & 74,6 \\
\hline & $\mathrm{CT}$ & 0,73 & 1556,0 & 617,4 & 21,1 & 8,5 & 19,8 & 9378 & 229 & 53,1 \\
\hline & $\mathrm{C} \bigoplus$ & 1,14 & 1826,0 & 938,2 & 75,6 & 13,1 & 33,5 & 13918 & 314 & 87,6 \\
\hline & $\mathrm{n}$ & 5 & 5 & 5 & 5 & 5 & 5 & 5 & 5 & 5 \\
\hline
\end{tabular}

\section{Mối quan hệ (tương quan) giữa các yếu tố hóa học với độ hạt trầm tích}

Kết quả tính toán tương quan giữa hàm lượng các chất hữu cơ và kim loại nặng với tỷ lệ bùn sét của trầm tích đã cho thấy chúng có tương quan rất chặt trong phần lớn các trường hợp. Hàm lượng các chất hữu cơ và kim loại nặng cao trong trầm tích có tỷ lệ bùn 
sét lớn trừ trường hợp của $\mathrm{Zn}$ và $\mathrm{HC}$ (bảng 4). Điều này cho thấy sự khác biệt trong hành vi của các nguyên tố. $\mathrm{Zn}$ và $\mathrm{HC}$ ít tham gia vào thành phần trầm tích qua sự hình thành các thể keo tụ (floculation).

Bảng 4: Tương quan giữa tỷ lệ bùn sét và các chất hữu cơ, kim loại nặng

\begin{tabular}{|c|c|c|}
\hline Yếu tố & Tháng 11/2008 & Tháng 4/2009 \\
\hline $\begin{array}{c}\text { C.hc }-\% \\
\text { bùn sét }\end{array}$ & $\mathrm{y}=0,0105 \mathrm{x}+0,1912\left(\mathrm{R}^{2}=0,9386\right)$ & $\mathrm{y}=0,0103 \mathrm{x}+0,2787\left(\mathrm{R}^{2}=0,8859\right)$ \\
\hline $\begin{array}{c}\text { N.hc - \% } \\
\text { bùn sét }\end{array}$ & $\mathrm{y}=14,529 \mathrm{x}+136,94\left(\mathrm{R}^{2}=0,9567\right)$ & $\mathrm{y}=20,322 \mathrm{x}+80,875\left(\mathrm{R}^{2}=0,931\right)$ \\
\hline $\begin{array}{c}\text { P.ts - \% } \\
\text { bùn sét }\end{array}$ & $\mathrm{y}=8,2811 \mathrm{x}+74,551\left(\mathrm{R}^{2}=0,968\right)$ & $\mathrm{y}=11,256 \mathrm{x}+45,525\left(\mathrm{R}^{2}=0,8998\right)$ \\
\hline $\begin{array}{c}\text { Zn - \% } \\
\text { bùn sét }\end{array}$ & $\mathrm{y}=0,4387 \mathrm{x}+22,12\left(\mathrm{R}^{2}=0,3792\right)$ & $\mathrm{y}=0,6877 \mathrm{x}+11,206\left(\mathrm{R}^{2}=0,8487\right)$ \\
\hline $\begin{array}{c}\text { Cu - \% } \\
\text { bùn sét }\end{array}$ & $\mathrm{y}=0,1333 \mathrm{x}+1,3191\left(\mathrm{R}^{2}=0,8385\right)$ & $\mathrm{y}=0,1314 \mathrm{x}+1,3691\left(\mathrm{R}^{2}=0,9457\right)$ \\
\hline $\begin{array}{c}\mathrm{Pb}-\% \\
\text { bùn sét }\end{array}$ & $\mathrm{y}=0,3213 \mathrm{x}+4,2974\left(\mathrm{R}^{2}=0,9051\right)$ & $\mathrm{y}=2,7777 \mathrm{x}-7,1514\left(\mathrm{R}^{2}=0,9842\right)$ \\
\hline $\begin{array}{c}\text { Fe - \% } \\
\text { bùn sét }\end{array}$ & $\mathrm{y}=111,01 \mathrm{x}+3945,2\left(\mathrm{R}^{2}=0,7735\right)$ & $\mathrm{y}=113,39 \mathrm{x}+4178,2\left(\mathrm{R}^{2}=0,9195\right)$ \\
\hline $\begin{array}{l}\mathrm{HC}-\% \\
\text { bùn sét }\end{array}$ & $\mathrm{y}=1,2597 \mathrm{x}+249,51\left(\mathrm{R}^{2}=0,2141\right)$ & $\mathrm{y}=1,855 \mathrm{x}+157,88\left(\mathrm{R}^{2}=0,6863\right)$ \\
\hline
\end{tabular}

Kết quả tính toán cho thấy trong 2 đợt khảo sát này các chất hữu cơ có các mối tương quan chặt chẽ với nhau (bảng 5).

Bảng 5: Tương quan giữa các chất hữu cơ trong trầm tích

\begin{tabular}{|c|c|c|}
\hline Yếu tố & Tháng 11/2008 & Tháng 4/2009 \\
\hline $\begin{array}{c}\text { P. ts - } \\
\text { N.hc }\end{array}$ & $\mathrm{y}=0,5634 \mathrm{x}+0,4597\left(\mathrm{R}^{2}=0,9887\right)$ & $\mathrm{y}=0,5411 \mathrm{x}+12,223\left(\mathrm{R}^{2}=0,9225\right)$ \\
\hline $\begin{array}{c}\text { N.hc }- \\
\text { C.hc }\end{array}$ & $\mathrm{y}=1269 \mathrm{x}-68,067\left(\mathrm{R}^{2}=0,8624\right)$ & $\mathrm{y}=1676,1 \mathrm{x}-261,5\left(\mathrm{R}^{2}=0,755\right)$ \\
\hline Pts - C.hc & $\mathrm{y}=735,1 \mathrm{x}-48,576\left(\mathrm{R}^{2}=0,9013\right)$ & $\mathrm{y}=982,71 \mathrm{x}-181,72\left(\mathrm{R}^{2}=0,8176\right)$ \\
\hline
\end{tabular}




\section{Tỉ số mol của các chất dinh dưỡng}

Kết quả tính toán cũng cho thấy tỷ số mol $\mathrm{C} / \mathrm{N}$ trong trầm tích đầm Thị Nại vào cả 2 đợt khảo sát đều có xu hướng giảm từ đỉnh đầm đến cửa đầm (bảng 6), điều này chứng tỏ trầm tích ở đỉnh đầm có nhiều vật chất lục nguyên hơn so với khu vực giữa và cửa đầm.

Bảng 6: Tỷ số $\mathrm{C} / \mathrm{N}$ và $\mathrm{N} / \mathrm{P}$ trong trầm tích

\begin{tabular}{|c|c|c|c|c|}
\hline \multirow{2}{*}{ Khu vực } & \multicolumn{2}{|c|}{ Mùa mưa, (11/2008) } & \multicolumn{2}{c|}{ Mùa khô, (4/2009) } \\
\cline { 2 - 5 } & $\mathbf{C} / \mathbf{N}$ & $\mathbf{N} / \mathbf{P}$ & $\mathbf{C} / \mathbf{N}$ & N/P \\
\hline \multirow{3}{*}{ Đỉnh đầm } & $14,69(\mathrm{n}=5)$ & $4,33(\mathrm{n}=5)$ & $20,0(\mathrm{n}=5)$ & $4,40(\mathrm{n}=5)$ \\
& $(6,37-21,71)$ & $(3,90-4,79)$ & $(9,6-31,3)$ & $(3,6-5,4)$ \\
\hline \multirow{2}{*}{ Giữa đầm } & $11,60(\mathrm{n}=5)$ & $4,19(\mathrm{n}=5)$ & $14,75(\mathrm{n}=5)$ & $4,14(\mathrm{n}=5)$ \\
& $(6,07-21,77)$ & $(3,62-5,40)$ & $(8,25-29,89)$ & $(3,04-7,06)$ \\
\hline \multirow{2}{*}{ Cửa đầm } & $10,41(\mathrm{n}=5)$ & $3,79(\mathrm{n}=5)$ & $7,12(\mathrm{n}=5)$ & $4,45(\mathrm{n}=5)$ \\
& $(7,63-15,21)$ & $(3,34-4,19)$ & $(5,36-9,32)$ & $(3,94-5,70)$ \\
\hline
\end{tabular}

Vào mùa khô, tỷ số $\mathrm{C} / \mathrm{N}$ trong khu vực cửa đầm khá thấp, gợi ý trầm tích vào mùa khô chịu ảnh hưởng nhiều hơn bởi nguồn vật chất khác (từ hoạt động con người). Điều này hợp lý vì khu vực phía Tây Nam đầm tiếp nhận nhiều nước thải (sinh hoạt và công nghiệp) của thành phố Quy Nhơn đổ ra. Ảnh hưởng của nước thải từ thành phố Quy Nhơn tương đối rõ hơn vào mùa khô vì vào mùa mưa lượng nước sông đưa ra rất lớn.

Tỉ số N/P dao động xung quanh 4 cho thấy tỉ lệ của $\mathrm{P}$ dạng vô cơ trong trầm tích không lớn lắm.

\section{Một số dẫn liệu về tốc độ lắng đọng trầm tích và thành phần vật liệu mới lắng đọng}

Kết quả tính toán TĐLĐTT và thành phần vật chất của vật liệu mới lắng đọng (bảng 7) cho thấy vào tháng 12/2008 (mưa lũ) TĐLĐTT cao hơn rất nhiều so với mùa khô (tháng 5/2009), nhưng hàm lượng của các chất hữu cơ và kim loại nặng trong vật liệu của bẫy trầm tích thường thấp hơn nhiều, nhất là tại 3 bẫy được đặt gần đỉnh đầm. Điều này, chủ yếu là do vào mùa mưa lũ, vật chất thô từ sông được đưa vào đầm nhiều (vật chất được lắng đọng trong các bẫy trầm tích cấu tạo chủ yếu bởi vật liệu cát hoặc cát chứa bùnsét) làm cho TĐLĐTT cao hơn so với mùa mưa. Ngược lại, vào mùa khô, vật chất lắng đọng trong các bẫy chủ yếu là các thể keo tụ (floculation) tạo ra ở nơi tiếp xúc giữa nước mặn và ngọt (vật chất lắng đọng trong các bẫy chủ yếu cấu tạo bởi vật liệu bùn-sét). 
Các dẫn liệu trong bảng 7 cũng cho thấy vào thời kỳ mưa lũ, sự lắng đọng vật chất diễn ra trong toàn đầm; vào mùa khô, vật chất được lắng đọng chủ yếu tại đỉnh đầm.

Bảng 7: Tốc độ lắng đọng trầm tích và thành phần vật liệu trong bẫy trầm tích

\begin{tabular}{|c|c|c|c|c|c|c|c|c|c|}
\hline Bẫy & $\begin{array}{c}\text { TĐLĐTT } \\
\left(\mathrm{g} / \mathrm{cm}^{2} / \text { ngày }\right)\end{array}$ & $\begin{array}{l}\text { C he } \\
(\%)\end{array}$ & $\begin{array}{l}\text { Nhc } \\
(\mu g / g)\end{array}$ & $\begin{array}{c}\text { Pts } \\
(\mu g / g)\end{array}$ & $\begin{array}{c}\mathrm{Zn} \\
(\mu g / g)\end{array}$ & $\begin{array}{c}\mathrm{Cu} \\
(\mu g / g)\end{array}$ & $\begin{array}{c}\mathrm{Pb} \\
(\mu g / g)\end{array}$ & $\begin{array}{c}\mathrm{Fe} \\
(\mu g / g)\end{array}$ & $\begin{array}{c}\text { Bùn } \\
\text { sét }(\%)\end{array}$ \\
\hline \multicolumn{10}{|c|}{$11 / 2008$} \\
\hline B 1 & 0,710 & 0,32 & 843,2 & 255,4 & 16,1 & 2,6 & 8,6 & 3544,6 & 12,04 \\
\hline B 2 & 0,281 & 1,36 & 1644,0 & 993,4 & 44,8 & 11,6 & 34,1 & 8365,7 & 65,37 \\
\hline B 3 & 0,473 & 1,28 & 1850,4 & 1100,6 & 54,8 & 13,5 & 33,7 & 9395,1 & 65,32 \\
\hline B 4 & 0,558 & 0,87 & 1563,2 & 872,6 & 45,9 & 10,1 & 22,0 & 6841,6 & 50,82 \\
\hline B 5 & 0,339 & 1,35 & 1457,4 & 913,9 & 53,4 & 13,3 & 38,5 & 9362,8 & 84,58 \\
\hline $\mathrm{TB}$ & 0,472 & 1,04 & 1471,6 & 827,1 & 43,0 & 10,2 & 27,4 & 7501,9 & 55,63 \\
\hline \multicolumn{10}{|c|}{$5 / 2009$} \\
\hline B 1 & 0,128 & 2,18 & 1565,9 & 872,5 & 93,6 & 14,2 & 42,9 & 22216,9 & 95,85 \\
\hline B 2 & 0,020 & 1,67 & 2193,2 & 1536,0 & 97,3 & 16,5 & 68,0 & 29269,4 & 89,37 \\
\hline B 3 & 0,013 & 1,54 & 2347,3 & 1690,0 & 77,0 & 13,0 & 55,8 & 29547,4 & 93,03 \\
\hline B 4 & 0,007 & 1,68 & 952,4 & 616,0 & 46,8 & 13,1 & 87,5 & 22946,0 & 93,02 \\
\hline B 5 & 0,008 & 1,84 & 1492,5 & 825,0 & 12,9 & 13,8 & 81,3 & 21429,4 & 94,94 \\
\hline $\mathrm{TB}$ & 0,035 & 1,78 & 1710,3 & 1107,9 & 65,5 & 14,1 & 67,1 & 25081,8 & 93,24 \\
\hline
\end{tabular}

B1.Gần đỉnh đầm; B 2. Gần cồn Trạng; B 3. Trên cầu Nhơn Hội;

B 4. Duới cầu Nhơn Hội, B 5. Gần cảng Thị Nại

Ngoài ra, sự khác biệt về thành phần hóa học của vật lơ lửng, của trầm tích mới lắng đọng trong bẫy trầm tích và trầm tích đầm Thị Nại (bảng 8) cho thấy vật chất hữu cơ và kim loại nặng thường tập trung nhiều nhất trong trầm tích mới lắng đọng, ít nhất trong trầm tích đáy. Điều này cho thấy sự khoáng hóa vật chất hữu cơ và tái hòa tan của kim loại nặng trong trầm tích có khả năng ảnh hưởng đến chất lượng môi trường nước. 
Bảng 8: So sánh giá trị trung bình của hàm lượng các chất hữu cơ và kim loại nặng trong các dạng vật liệu khác nhau

\begin{tabular}{|c|c|c|c|c|c|c|c|c|}
\hline & $\begin{array}{c}\text { Thòi } \\
\text { gian }\end{array}$ & $\begin{array}{c}\mathbf{C} \mathbf{h c} \\
(\boldsymbol{\%})\end{array}$ & $\begin{array}{c}\mathbf{N} \\
(\mu \mathrm{g} / \mathrm{g})\end{array}$ & $\begin{array}{c}\mathbf{P} \\
(\mu \mathrm{g} / \mathbf{g})\end{array}$ & $\begin{array}{c}\mathbf{Z n} \\
(\mu \mathrm{g} / \mathrm{g})\end{array}$ & $\begin{array}{c}\mathbf{C u} \\
(\mu \mathrm{g} / \mathrm{g})\end{array}$ & $\begin{array}{c}\mathbf{P b} \\
(\mu \mathrm{g} / \mathrm{g})\end{array}$ & $\begin{array}{c}\mathbf{F e} \\
(\mu \mathrm{g} / \mathbf{g})\end{array}$ \\
\hline \multirow{2}{*}{ Vật lơ lửng } & $11 / 2008$ & - & 1102,7 & 858,1 & 61,8 & 8,9 & 16,2 & 8958 \\
\cline { 2 - 9 } & $5 / 2009$ & - & 1451,5 & 917,4 & 18,2 & 2,5 & 7,7 & 1687 \\
\hline \multirow{2}{*}{$\begin{array}{c}\text { Trầm tích mới lắng đọng } \\
\text { (trong bẫy trầm tích) }\end{array}$} & $11 / 2008$ & 1,04 & 1471,6 & 827,1 & 43,0 & 10,2 & 27,4 & 7502 \\
\cline { 2 - 9 } & $5 / 2009$ & 1,78 & 1710,3 & 1107,9 & 65,5 & 14,1 & 67,1 & 25082 \\
\hline \multirow{2}{*}{ Trầm tích đáy } & $11 / 2008$ & 0,53 & 607,0 & 342,5 & 36,3 & 5,6 & 14,7 & 7537 \\
\cline { 2 - 9 } & $5 / 2009$ & 0,69 & 899,4 & 498,9 & 38,9 & 6,7 & 17,1 & 8746 \\
\hline
\end{tabular}

Ghi chú: “-“: không phân tích

\section{THẢO LUẬN}

\section{1. Đánh giá chất lượng môi trường trầm tích}

Trầm tích trong khu vực đầm Thị Nại có hàm lượng các chất hữu cơ và kim loại thay đổi trong phạm vi rộng. Do quy chuẩn Việt Nam không qui định các mức cho phép đối với trầm tích nên các tài liệu nước ngoài liên quan đến vấn đề này đã được tham khảo để đánh giá chất lượng trầm tích.

Về hàm lượng của các chất hữu cơ trong trầm tích, theo Hyland et al., 2000 các trầm tích có dưới $0,05 \%$ và trên $3 \%$ chất hữu cơ sẽ làm giảm sự phong phú cũng như sinh khối của sinh vật đáy mềm. Như vậy trầm tích ở khu vực nghiên cứu (với hàm lượng $\mathrm{C}$ hữu cơ dao động từ $0.09-1,14 \%$ ) đều thích hợp cho đời sống thủy sinh. Chúng cũng thấp hơn giá trị $2 \%$ theo qui định của Trung Quốc về hàm lượng $\mathrm{C}$ hữu cơ trong chuẩn mực trầm tích dùng bảo vệ đời sống thủy sinh.

Về mức hàm lượng các kim loại nặng, có thể áp dụng các khái niệm ngưỡng tác động (threshold effect level, TEL) và mức có thể gây tác động (probable effect level, PEL) (CCME - Canadian Council of Ministers of the Environment - 2003) với mục đích bảo vệ đời sống thủy sinh. Trong bảng 9 các hàm lượng các kim loại trong trầm tích đầm Thị Nại được so sánh với TEL và PEL. Các giá trị trong bảng này cho thấy hàm lượng các kim loại 
nặng trong trầm tích đầm Thị Nại chưa vượt quá phạm vi cho phép với mục đích bảo vệ đời sống thủy sinh.

Bảng 9: So sánh hàm lượng của các kim loại nặng trong trầm tích đầm Thị Nại với TEL, PEL và chuẩn mực trầm tích Trung Quốc

\begin{tabular}{|c|c|c|c|c|}
\hline \multirow{2}{*}{$\begin{array}{c}\text { Thời } \\
\text { gian } \\
\text { thu mâu }\end{array}$} & Giá Trị & Zn (ppm) & Cu (ppm) & Pb (ppm) \\
\cline { 2 - 5 } & TEL & 124 & 18,7 & 30,2 \\
\cline { 2 - 5 } & $\begin{array}{c}\text { Chuẩn Mực Trung } \\
\text { Quốc }\end{array}$ & 150 & 108 & 112 \\
\hline \multirow{2}{*}{$\begin{array}{c}\text { Mùa mưa } \\
(11 / 2008)\end{array}$} & $\begin{array}{c}\text { Trung bình } \\
\text { Dao động }\end{array}$ & $3,4-83,0$ & $0,1-15,3$ & 60 \\
\hline Mùa khô & Trung bình & 38,9 & $6,3-35,2$ \\
\hline (4/2009) & Dao động & $7,9-75,6$ & $0,9-13,1$ & $2,8-33,5$ \\
\hline
\end{tabular}

\section{Các yếu tố ảnh hưởng đến chất lượng trầm tích đầm Thị Nại}

\section{a. Vật chất tù̀ tụ nhiên}

Đầm Thị Nại là nơi tiếp nhận vật chất từ lưu vực các các sông Côn và Hà Thanh. Sông Côn đổ vào khu vực đỉnh đầm. Sông có chiều dài $171 \mathrm{~km}$ với lưu lượng trung bình năm 4.300 triệu $\mathrm{m}^{3}$. Sông Hà Thanh đổ vào khu vực tây nam của đầm Thị Nại với lưu lượng trung bình năm là 750 triệu $\mathrm{m}^{3}$ (Nguyễn Tấn Hương, 2005). Lượng vật chất từ 2 con sông này đổ vào đầm khá lớn, nhất là vào mùa mưa, và chủ yếu ở dạng lơ lửng (bảng 10).

Do lượng vật chất từ sông đổ vào đầm khá lớn nên TĐLĐTT trong đầm Thị Nại tương đối cao vào mùa mưa. Nếu so sánh với TĐLĐTT trong đầm Thủy Triều - vịnh Cam Ranh (dao động từ 0,0032 - 0,0282, trung bình cả năm $0,0132 \mathrm{~g} / \mathrm{cm}^{2} /$ ngày, Phạm Văn Thơm, 2008), đây là khu vực có ít dòng sông lớn đổ vào, có thể thấy đầm Thị Nại có tốc độ lắng đọng trầm tích lớn hơn nhiều. Riêng khu vực đỉnh đầm, TĐLĐTT phụ thuộc rất nhiều vào sự hiện diện của cồn Chim. 
Bảng 10: Lượng vật chất đổ vào cửa đầm Thị Nại qua hệ thống thủy văn lục địa

\section{Sông Côn}

\begin{tabular}{|c|c|c|c|c|c|c|c|c|c|c|}
\hline $\begin{array}{c}\text { Vật LL } \\
\text { tấn }\end{array}$ & $\begin{array}{c}\mathrm{NH}_{3,4}-\mathrm{N} \\
\mathrm{kg}\end{array}$ & $\begin{array}{c}\mathrm{NO}_{2}-\mathrm{N} \\
\mathrm{Kg}\end{array}$ & $\begin{array}{c}\mathrm{NO}_{3}-\mathrm{N} \\
\mathrm{kg}\end{array}$ & $\begin{array}{c}\text { Tổng N } \\
\text { kg }\end{array}$ & $\begin{array}{c}\mathrm{PO}_{4}-\mathrm{P} \\
\mathrm{kg}\end{array}$ & $\begin{array}{c}\text { Tổng P } \\
\text { kg }\end{array}$ & $\begin{array}{l}\mathrm{Zn} \\
\mathrm{kg}\end{array}$ & $\begin{array}{l}\mathrm{Fe} \\
\mathrm{kg}\end{array}$ & $\begin{array}{l}\mathrm{Cu} \\
\mathrm{kg}\end{array}$ & $\begin{array}{l}\mathrm{Pb} \\
\mathrm{kg}\end{array}$ \\
\hline \multicolumn{11}{|c|}{ Mùa mưa } \\
\hline 153.606 & 172.000 & 56.569 & 433.591 & 2.559 .176 & 59.913 & 257.761 & 36.292 & 4.242 .667 & 4.013 & 3.956 \\
\hline \multicolumn{11}{|c|}{ Mùa khô } \\
\hline 33.863 & 129.000 & 12.792 & 330.849 & 1.413 .445 & 37.428 & 147.633 & 16.125 & 1.207 .583 & 1.768 & 1.792 \\
\hline \multicolumn{11}{|c|}{ Cả năm } \\
\hline \begin{tabular}{|l|}
187468 \\
\end{tabular} & 301.000 & 69.361 & 764.440 & 3.972 .622 & 97.341 & 405.394 & 52.417 & 5.450 .250 & 5.781 & 5.748 \\
\hline
\end{tabular}

\section{Sông Hà Thanh}

\begin{tabular}{|c|c|c|c|c|c|c|c|c|c|c|c|}
\hline $\begin{array}{c}\text { Vật LL } \\
\text { tấn }\end{array}$ & $\begin{array}{c}\mathbf{N H}_{3,4}-\mathbf{N} \\
\mathbf{k g}\end{array}$ & $\begin{array}{c}\mathbf{N O}_{2}-\mathbf{N} \\
\mathbf{K g}\end{array}$ & $\begin{array}{c}\mathbf{N O}_{3}-\mathbf{N} \\
\mathbf{K g}\end{array}$ & $\begin{array}{c}\text { Tổng N } \\
\mathbf{k g}\end{array}$ & $\begin{array}{c}\mathbf{P O}_{\mathbf{4}}-\mathbf{P} \\
\mathbf{k g}\end{array}$ & $\begin{array}{c}\text { Tổng P } \\
\mathbf{k g}\end{array}$ & $\begin{array}{c}\mathbf{Z n} \\
\mathbf{k g}\end{array}$ & $\begin{array}{c}\mathbf{F e} \\
\mathbf{k g}\end{array}$ & $\begin{array}{c}\mathbf{C u} \\
\mathbf{k g}\end{array}$ & $\begin{array}{c}\mathbf{P b} \\
\mathbf{~ k g}\end{array}$ \\
\hline \multicolumn{10}{|c|}{ Mùa mưa } \\
\hline 51.213 & 22.750 & 6.650 & 37.375 & 401.525 & 5.600 & 44.075 & 6.063 & 749.375 & 713 & 875 \\
\hline \multicolumn{8}{|c|}{ Mùa khô } \\
\hline 5.984 & 15.250 & 1.428 & 40.687 & 224.927 & 5703 & 29731 & 3125 & 186750 & 308 & 354 \\
\hline \multicolumn{8}{|c|}{ Cả năm } \\
\hline 57197 & 38.000 & 8.078 & 78.062 & 626.452 & 11303 & 73806 & 9188 & 936125 & 1021 & 1229 \\
\hline
\end{tabular}

Nguồn: Phạm Văn Thơm và Lê thị Vinh, 2009

\section{b. Vật chất tù̀ các hoạt động kinh tế xã hội}

Trong khu vực đầm Thị Nại, bên cạnh hoạt động nuôi trồng và khai thác thủy sản, các hoạt động nông nghiệp, công nghiệp, dịch vụ hàng hải và sinh hoạt dân cư cũng thải ra nhiều chất gây ô nhiễm. Nước thải tại một số cống thải thành phố và cơ sở chế biến thủy sản tỉnh Bình Định thường có nồng độ vật $\mathrm{LL}$, ammonia, phosphate, giá trị $\mathrm{BOD}_{5}, \mathrm{COD}$ cao hơn các giới hạn cho phép qui định trong QCVN: 2008/BTNMT và điều kiện vệ sinh cộng đồng quanh đầm còn yếu kém (Lê Thị Vinh và Nguyễn Thị Thanh Thủy, 2009). Các chất gây nhiễm bẩn này không chỉ ảnh hưởng đến chất lượng nước mà còn có thể sẽ tham gia vào trầm tích đáy bởi quá trình tạo keo tụ (floculation). 


\section{NHẬN XÉT}

Từ các dẫn liệu trình bày trên đây có thể đưa ra một số nhận xét như sau:

1. Hàm lượng các chất hữu cơ và kim loại nặng trong trầm tích đầm Thị Nại có xu hướng tăng dần từ đỉnh đầm về phía cửa đầm. Có sự tương quan mật thiết giữa độ hạt trầm tích và hàm lượng các chất hữu $c o, \mathrm{Fe}, \mathrm{Cu}$ và $\mathrm{Pb}$. Giữa các chất dinh dưỡng cũng có sự tương quan khá chặt. Ngoài ra, tỉ số mol $\mathrm{C} / \mathrm{N}$ gợi ý sự ưu thế của vật chất hữu cơ lục nguyên; sự ưu thế này giảm theo trục đầm vào mùa khô.

2. Chất lượng môi trường trầm tích đầm Thị Nại khá tốt, hàm lượng các chất hữu cơ và kim loại nặng trong trầm tích đầm Thị Nại đều phù hợp với mục đích bảo vệ đời sống thủy sinh.

3. Các yếu tố ảnh hưởng đến chất lượng trầm tích đầm Thị Nại gồm vật chất từ tự nhiên và các hoạt động kinh tế - xã hội trong khu vực liền kề. Các nguồn thải từ hoạt động con người có khả năng làm tăng cao tỷ lệ $\mathrm{N}, \mathrm{P}$ trong trầm tích.

4. Vào thời kỳ mưa lũ, vật chất được lắng đọng trong toàn đầm trong lúc vào mùa khô hiện tượng này chủ yếu diễn ra trong khu vực đỉnh đầm. TĐLĐTT vào mùa mưa cao hơn so với mùa khô nhưng hàm lượng các chất hữu cơ và kim loại nặng trong vật liệu trầm tích mới lắng đọng có xu thế ngược lại.

\section{TÀI LIỆU THAM KHẢO}

1. CCME , 2003. Canadian Environmental Quality Guidelines (online publication).

2. Cheng Liu, Zhao-Yin Wang, Yun He and Heping Wei, 2003. Water Quality and Sediment Quality of Waters near Shanghai sewage outfalls - International Conference on Estuaries and Coasts - November 9-11, 2003, Hanzhou, China - pp 646-654.

3. Nguyễn Hũu Huân, Lê Lan Hương, Võ Duy Sơn, Lê Trần Dũng, Lê Hoài Hương, 2006. Chất lượng môi trường nước đầm Thị Nại- vịnh Qui Nhơn. Tuyển tập nghiên cứu biển.Tập XV. 105-116.

4. Nguyễn Tấn Hương, 2005. Đặc điểm khí tượng thuỷ văn tỉnh Bình Định. Sở Khoa học và Công nghệ tỉnh Bình Định, đài khí tượng thủy văn khu vực Nam Trung bộ.

5. FAO, 1975. Manual of Methods in Aquatic Environment Research- Part2: Methods for Detection, Measurement and Monitoring of water polution. 
6. Phạm Văn Thơm, 2008. Báo cáo tổng kết đề tài “ Điều tra hiện trạng môi trường vịnh Cam Ranh để phục vụ phát triển kinh tế - xã hội thị xã Cam Ranh”. Đề tài hợp đồng với Sở Khoa học và Công nghệ, Khánh Hòa.

7. Phạm Văn Thơm, Lê Thị Vinh, 2009. Đánh giá tác động của các hoạt động con người đến môi trường đầm Thị Nại. Báo cáo chuyên đề. Nhiệm vụ "Nghiên cứu $c o$ " sở khoa học nhằm xây dưng các giải pháp phát triển nuôi trồng thủy sản bền vĩng tại đầm Thị Nại, tỉnh Bình Định". Chủ nhiệm Nguyễn Thị Thanh Thủy.

8. Lê Thị Vinh, Nguyễn Thị Thanh Thủy, 2009. Một số vấn đề liên quan đến chất lượng môi trường nước đầm Thị Nại, tỉnh Bình Định. Kỷ yếu hội thảo khoa học công nghệ, môi trường và phát triển bền vững ở duyên hải miền Trung. 196-205.

\title{
ENVIRONMENTAL QUALITY OF SEDIMENTS IN THI NAI LAGOON, BINH DINH
}

\author{
LE THI VINH, NGUYEN THI THANH THUY, TONG PHUOC HOANG SON \\ DUONG TRONG KIEM, NGUYEN HONG THU, PHAM HUU TAM, PHAM HONG NGOC
}

\begin{abstract}
Summary: The paper represents some aspects on the quality of the sediments in Thi Nai lagoon. Results of 2 surveys (performed in November 2008, rainy season, and April 2009, dry season) show that the contents of the organic materials and heavy metals in the sediment were considerably various (organic C: $0.09-1.16 \%$, organic $N: 88.7-1826.0 \mu \mathrm{g} / \mathrm{g}$, total P: 44.2 $938.2 \mu \mathrm{g} / \mathrm{g} ; \mathrm{Zn:} 3.4$ - $75.6 \mu \mathrm{g} / \mathrm{g} ; \mathrm{Cu}: 0.1$ - $15.3 \mu \mathrm{g} / \mathrm{g}, \mathrm{Pb}: 2.3$ - $35.2 \mu \mathrm{g} / \mathrm{g}, \mathrm{Fe}: 1379$ - 14981 $\mu \mathrm{g} / \mathrm{g} ; \mathrm{HC}: 108$ - $423 \mu \mathrm{g} / \mathrm{g}$ ). Content of organic matters, heavy metals and hydrocarbon increases from the top toward the mouth of the lagoon because of the increase of pelite fraction in the sediments. The most part of the organic matters are terrigeneous in origin particularly in rainy season.

Generally, the sediment in Thi Nai lagoon, in term of organic materials and heavy metals, was suitable for the aquatic life. The factors affecting to the sediment quality included the materials from natural sources (mainly from Con and Ha Thanh rivers) and human activities. In the rainy season, the deposition on the sediment took place in the whole of the lagoon, whereas during the dry season, it prevailed mainly in the top of the lagoon. Sedimentation rate was higher in rainy season compared to dry season but the contents of the organic matters and heavy metals of materials in sediment traps were higher in dry season.
\end{abstract}

Ngày nhận bài: 12 - 01 - 2010

Ngưòi nhận xét: TS. Trịnh Thế Hiếu 